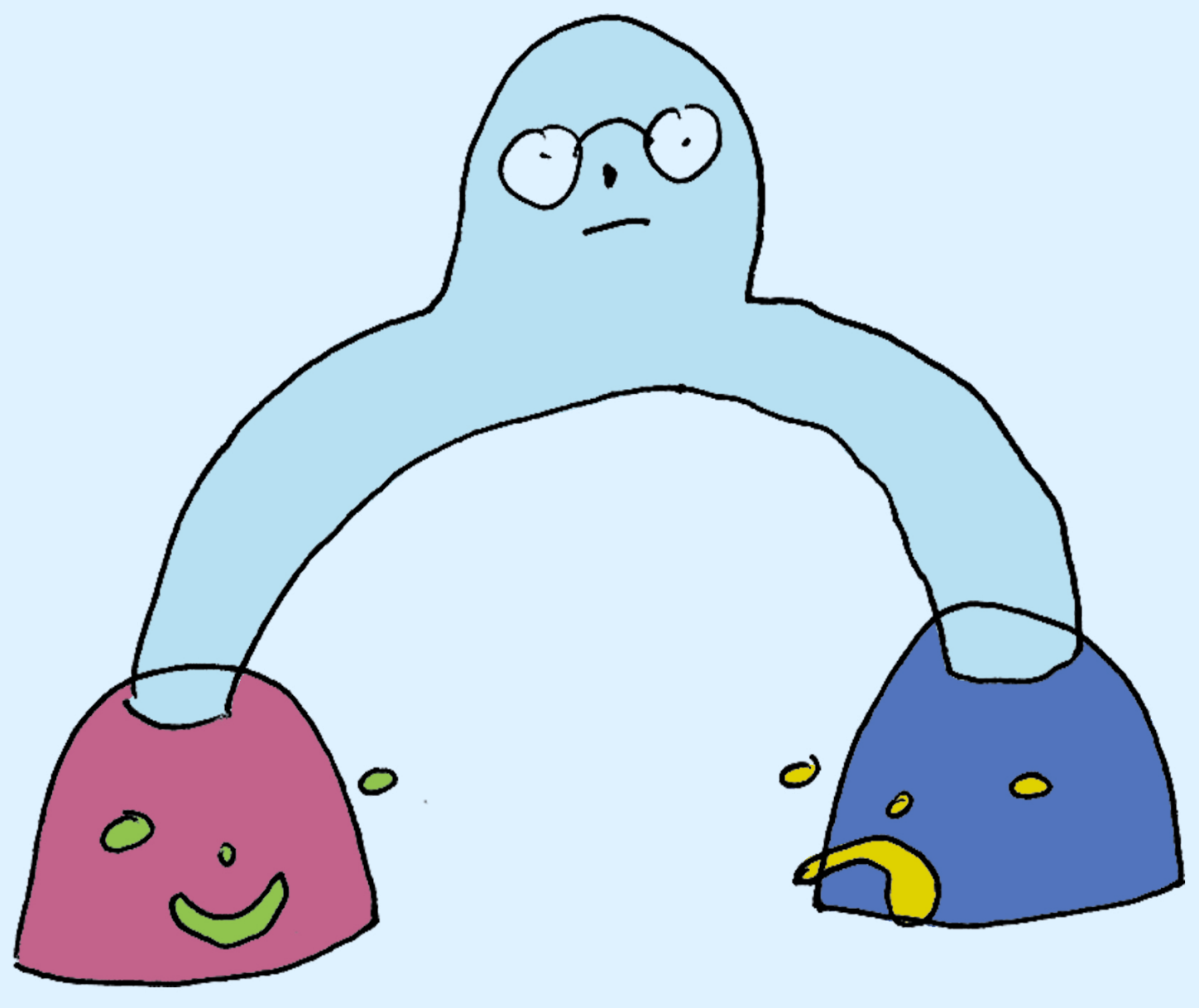


Reseña de

Sector cultural,

claves de acceso,

de Eduardo

Cruz Vázquez

Jorge Nicolás Russ Moreno 


\section{Reseña de Sector cultural, claves de acceso, de Eduardo Cruz Vázquez}

\section{Jorge Nicolás Russ Moreno}

¿Si fueras el director de Bellas Artes, permitirías que se presentara Vicente Fernández? Esa fue la pregunta la hizo Alejandro Soberón (CEO de Grupo (IE) al autor del libro "Sector cultural, claves de acceso", Eduardo Cruz Vázquez (p. 9). La respuesta fue un sí.

Esta pregunta y su respuesta, nos plantean algo inquietante sobre la cultura actual y cómo abordarla desde la gestión pública. ¿Es algo sagrado que debe permanecer custodiada como tesoro de unos pocos?

El escrito nace con la referencia propia del autor en el ámbito de las prácticas y la gestión cultural por más de veinte años.

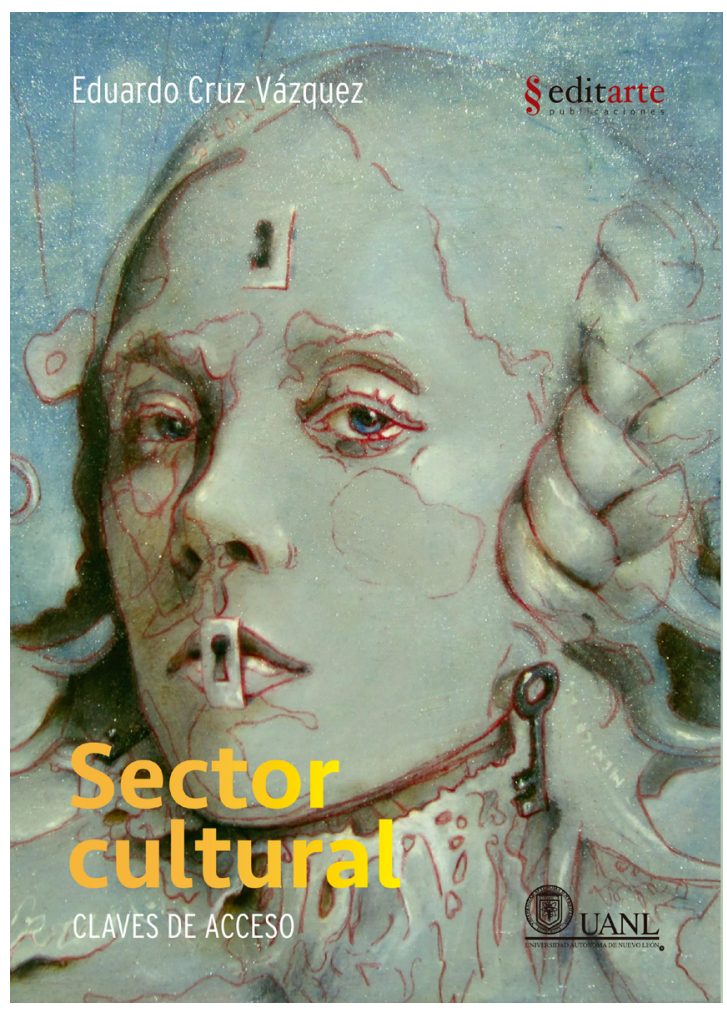

Viejos conceptos, nuevos conceptos. En los años noventa, él ya elaboraba principios modernos para la época de promoción y difusión de la cultura en un momento histórico en que la visión de la cultura era completamente institucional. Se tenían instancias gubernamentales que delimitaban su radio de acción.

Al parecer, los antropólogos han sido los culpables de la ambigüedad actual del concepto y percepción del término "cultura". Al revisar las distintas definiciones, tanto institucionales 
(Instituto Nacional de Estadística y Geografía, INEGI), como de la Organización de las Naciones Unidas para la Educación, la Ciencia y la Cultura (UNESCO), él nos simplifica y da su interpretación sobre ella:

Creación individual o colectiva, que es convertida en un bien, servicio y/o producto para su inserción en el mercado, que puede ser sujeto de protección legal, y que transmite uno o varios significados que le dan atributos simbólicos, materiales y de valor para su adquisición, apropiación, consumo y preservación por cualquier persona o grupo. (p.32)

Cruz Vázquez elabora una construcción conceptual de "empresa cultural", con el fin de entender el proceso productivo en el que estaría incluído este sector. No hay manera de medir económicamente el éxito o fracaso de las actividades culturales sin una medición unitaria.

Por empresa cultural entenderemos a la unidad económica que desempeña una actividad productiva legalmente establecida, basada en bienes, servicios, mercancías y /o productos que están constituidos fundamentalmente por un componente creativo en su cadena de producción. De igual manera, la empresa cultural coloca en circulación valores simbólicos para la sociedad y que no necesariamente tienen producción masiva ligada a corporativos nacionales y/o extranjeros para cubrir mercados locales y globales ... incluye a quienes trabajan bajo el régimen de honorarios profesionales, a las personas físicas con actividad empresarial, a distintas formas jurídicas en que se constituyen las micro, pequeñas, medianas y grandes empresas. Se toman en cuenta también a fundaciones, asociaciones civiles, sociedades civiles y fideicomisos, entre otras figuras (...). (p.32)

La aglomeración de todas estas empresas culturales darían por sentado la idea de un Sector Cultural (económicamente hablando). Pero primero habría que entender por qué no se habla todavía de manera abierta de dicho sector. 
Para el autor, siempre hay que ver el comportamiento de la economía. Lo interesante es ver las reacciones sobre la cultura institucionalizada y la que emerge desde otras latitudes fuera del ámbito gubernamental. Ese comportamiento económico impacta directamente sobre el trato generalizado a ese sector. De una manera autodidacta, el autor da sus impresiones y análisis sobre el sector de la cultura a través de esos años de transición de lo institucional a la coyuntura que significó en todos los sentidos para el país el ingreso al Tratado de Libre Comercio de América del Norte (TLCAN). Aunque en la revisión de las conclusiones del autor sobre el tratado (a niveles culturales), pareciera que el sector ha sido el que menos ha cambiado por dicho acuerdo.

Parecería que el debate sobre el TLCAN y todos sus derivados mantiene una carga negativa en el imaginario del país. No hay que olvidar que la visibilidad de la economía creativa se evidencia con la adopción del Sistema de Clasificación Industrial de América del Norte (SCIAN); es un catálogo de análisis sectorial de las principales industrias) el cual pone de manifiesto del Sector Cultural como una proyección de la economía incuestionable. Es decir, pasó de un bien intangible e incuantificable a una industria generadora de movimientos en la economía. (p. 58)

Previo a estos años, la cultura y su industria se mantenían entre el mecenazgo, en la inyección estatal a los aparatos burocráticos a ese sector ambiguo que deambulaba entre la educación, las bellas artes y el entretenimiento. Ahora se plantea como un área de oportunidad creciente, con resultados directos al PIB (Producto Interno Bruto).

Probablemente es el fin del nacionalismo cultural, que dio a luz algunas de las mentiras fundadoras de la configuración de este sector tuvo en el siglo XX. En esta necesidad de engrandecer las ideas progresistas con la identidad construida del México en desarrollo, la creación de mitos y protección a la cultura pareciera ahora ser un contrapeso al desarrollo de la misma. 
Al entrar en vigor el Tratado de Libre Comercio de América del Norte en 1994, era lógico que el intercambio comercial con los demás países permeará directamente en el crecimiento de intercambio cultural. Esto quiere decir que estas actividades dejan de ser del ámbito institucional para parecerse más al modelo comercial de Estados Unidos donde la privatización del sector plantea nuevos escenarios.

Después de tres décadas de ajuste al modelo estructural del país, aún falta el reconocimiento del sector de la cultura y lo que significa para el desarrollo. El autor expone las razones que él considera que han detenido este proceso evolutivo del sector cultural:

1 El nacionalismo y su visión tradicional de la cultura, el cual se opone al sentido económico y comercial de la misma. Este fervor se aferra al Estado subsidiario y dador de recursos, el cual no debería tener un sentido lucrativo.

2 La segunda razón atañe al sistema de clasificación industrial que nos rige.

En teoría, el discutido SCIAN debería incluir todas aquellas actividades del sector cultural, pero el mismo modelo de resistencia expuesto en el punto 1, desaceleran la tipificación y ampliación de todos los elementos que conectan la economía creativa.

Actualmente, el mayor peso que concentra la economía cultural, la sostienen las micro, pequeñas y medianas empresas ó Mipymes (p. 46). El autor busca los eslabones entre los grandes conglomerados de prestadores de servicios (por ejemplo las telefónicas, las tiendas departamentales o de autoservicio) con aquellas industrias que hacen convenio con ellas (librerías, distribuidores de música, museos, acuarios, becas y espectáculos). Esta búsqueda de uniones y convenios nos deja ver que todavía no hay un gran conglomerado de industrias culturales. Hay que buscar esas conexiones para entenderla.

Para este momento histórico, él ve como necesaria la constitución de estos clusters y ciudades creativas, más allá del panorama en el que se desarrollan localmente. La consolidación de estos clusters (hay quien habla de corredores culturales, circuitos o aglomeraciones 
creativas), llevaría a esas instancias jurídicas (Mipymes) a una evolución en el contexto de la creatividad, innovación y competitividad en el sector.

Una de las preguntas que se hace el autor es ¿para qué crear empresas culturales? Por cuestiones económicas, cuando la economía está en índices bajos, nada como el emprendurismo como motor de desarrollo. Poca oferta de trabajo en los jóvenes, hace que se cuestionen su entorno laboral y aterricen propuestas innovadoras que resuelven con asertividad esa falta de empleo y oportunidades. La terciarización (después de los insumos o materias primas y su industrialización, el tercer proceso económico es llamado así) de la economía conviene a los grandes intereses o bien es la única salida que se ha dejado para las naciones emergentes.

La obra plantea construir en su discurso la identificación de las etapas de un diseño de proyectos de empresa cultural para que el emprendedor tenga bases y no fracase por procesos que no sirvieron y que deberían fungir como texto para el ámbito profesional como un manual asertivo:

1 Descripción de la idea o el negocio.

2 Análisis cuantitativo y cualitativo de su viabilidad en el sector y el mercado cultural.

3 Etapas que propone cumplir para convertirse en bien, servicio, mercancía y/o producto o plan de negocios.

4 Analizar las formas o mecanismos de financiamiento a los que podría recurrir para emprender el negocio o bien plan de inversión.

5 Conceptualizar un diseño de marca y una estrategia de marketing o estrategia general de mercado. 
Para crear la empresa cultural, el emprendedor debe conocer los fenómenos culturales que al final, también son económicos. Debe dominar el ámbito de la economía general y la economía cultural en particular. E especializarse en los dos puntos anteriores le permite llegar al tercer campo: el análisis sectorial para entender el "yo lo produzco porque tú lo necesitas." De ahí se debe elaborar el proyecto integral de la empresa, que conduce al quinto escenario: el ecosistema financiero. Y para concluir el ciclo de creación empresarial, es el dominio del ser y la persona, es decir, la fortaleza para entender que un proyecto de emprendedor puede fracasar y se debe pasar al siguiente. Que hay etapas y que jamás se debe elaborar un solo proyecto y apostar a uno solo: hay que elaborar conjuntos de ellos.

En esa fiebre de aciertos y desaciertos de hoy, Cruz Vázquez pone de manifiesto que no se debe caer en la changarrización creativa: negocios que dependen únicamente de la tecnología como fin último y no tienen enfoque, ya que consideran la misma creatividad como un producto y son incapaces de evolucionar a mediano y largo plazo por esa limitación en la visión empresarial y que sus productos no respondan al mercado.

El momento álgido del texto de Cruz Vázquez está en la explicación de cómo se introduce el sector cultural en la vida económica del país. La llamada Cuenta Satélite de la Cultura: un verdadero rompecabezas para poder armar la vida cultural del país a través de sus indicadores, las empresas culturales, los sectores que conforman las distintas piezas para entender el conglomerado del gran sector cultural.

En el formato de esta cuenta, analiza los elementos del 2008 al 2013 para entender la actualidad de él. Lo interesante del análisis es que habla de la socialización entre las distintas entidades del sector en esa conformación de la "comunidad cultural". Esta cuenta es la primera lectura a la contribución de la cultura al PIB. Una primera revisión nos dice que el sector no ha crecido.

Además, desenmascara el mito de que la cultura institucional como salvadora del sector. Los datos muestran que la inversión del Estado en esta materia no sostiene al sector. 
Después de entender estos elementos como conformación de un sector económico, hay que contemplar la forma de integración de este sector a la economía internacional: la diplomacia, cooperación y comercio cultural.

Cruz Vázquez aborda la diplomacia cultural, recalcando la necesidad de volverse independiente y autónoma, que se convierta en eje articulador de una agenda de intereses y que vaya más allá de la mera exportación de valores simbólicos de la cultura nacionalista; y que en realidad es un lastre para la verdadera práctica del soft power (las acciones a través de medios culturales complementados de medios diplomáticos ) y la propalación de la marca-país (el imaginario y lo simbólico para construir la imagen de un estado). Adicionalmente, constituiría una buena fuente de empleos.

Solo una reestructuración institucional de la cultura podría optimizar y volver al sector cultural como un ente poderoso en la vida del país. El autor plantea un esquema de trabajo y operaciones para la recién formada Secretaría de Cultura. Básicamente es un sector cultural sólido, dividido en tres subsectores que engloban las instituciones educativas y sin fines de lucro, el subsector del Estado, el subsector de las MiPymes. Estos subsectores se dividirían en subsectores, ramas y subramas. Debajo de ellas estarían las actividades propias del sector y de sus subdivisions. (Figura 1) 


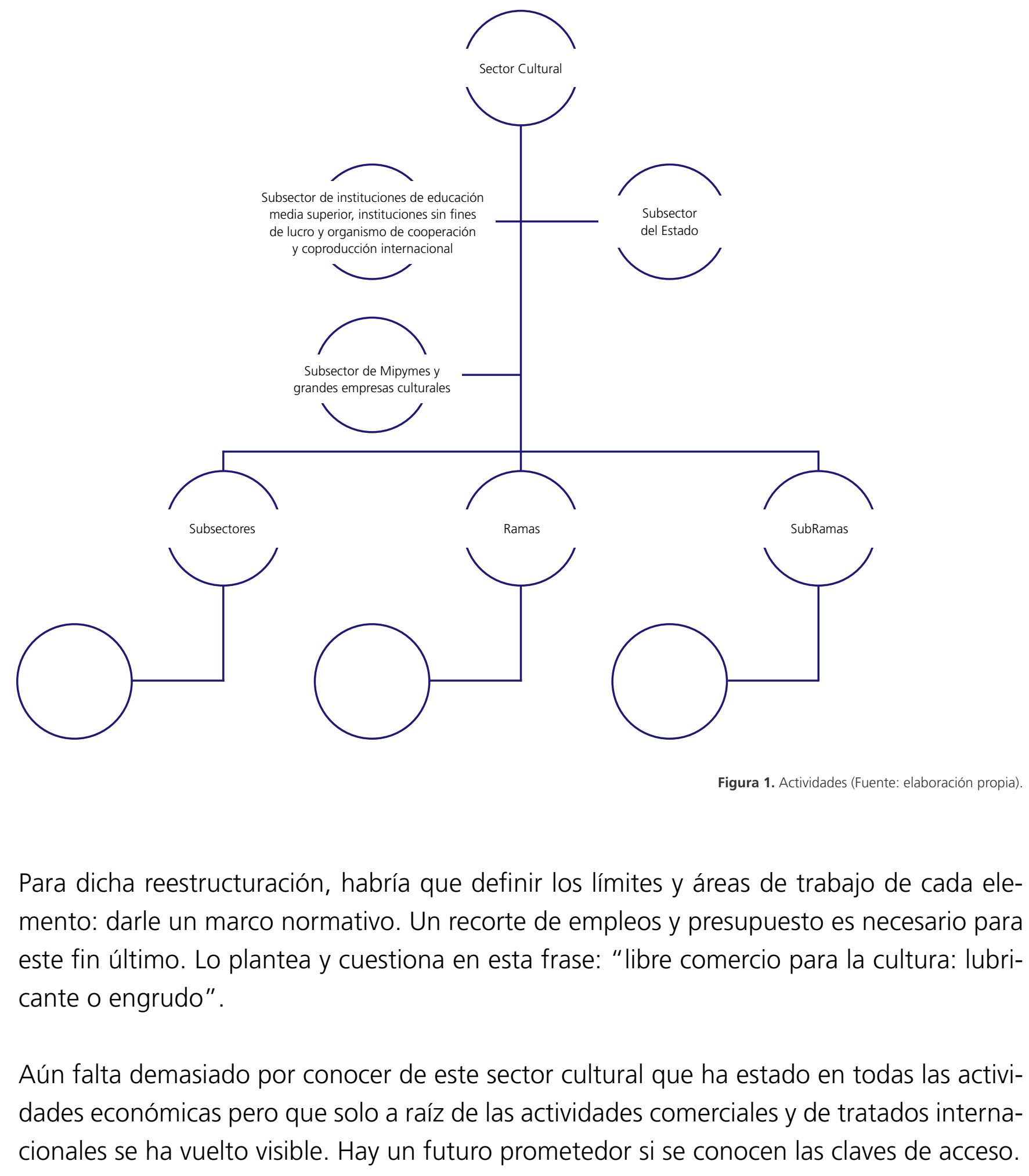




\section{Referencias}

Cruz, E. (2016) Sector cultural. Claves de acceso.

Nuevo León, México: Editarte, pp.166,

ISBN: 978-607-97260-0-3 